University of Massachusetts Amherst ScholarWorks@UMass Amherst

Communication Department Faculty Publication

Series

Communication

2017

\title{
Practices of topic and dialogue activity management in dispute mediation
}

Alena L. Vasilyeva

University of Massachusetts Amherst

Follow this and additional works at: https://scholarworks.umass.edu/communication_faculty_pubs Part of the Communication Commons

\section{Recommended Citation}

Vasilyeva, Alena L., "Practices of topic and dialogue activity management in dispute mediation" (2017). Discourse Studies. 50. https://doi.org/10.1177/1461445617701993

This Article is brought to you for free and open access by the Communication at ScholarWorks@UMass Amherst. It has been accepted for inclusion in Communication Department Faculty Publication Series by an authorized administrator of ScholarWorks@UMass Amherst. For more information, please contact scholarworks@library.umass.edu. 
"Paper for DISCOURSE STUDIES, 19:3"

Practices of Topic and Dialogue Activity Management in Dispute Mediation

\author{
Alena L. Vasilyeva \\ Version 3 October 10, 2016 \\ Department of Communication \\ University of Massachusetts Amherst \\ N368 Integrative Learning Center \\ 650 North Pleasant Street \\ Amherst MA 01003 \\ USA \\ vasilyeva@umass.edu
}

Short title: Dispute Mediation

Size: 9096 words 
Practices of Topic and Dialogue Activity Management in Dispute Mediation Abstract

This study examines the mediator practices to bring the interaction back on track when the participants of dispute mediation go off-task. An existing collection of 18 transcripts from audio recordings of mediation sessions at a mediation center in the western United States serves as a source of interactional data. First, the study examines the moves mediators make to perform interventions to bring the current state of activity more in line with mediation activity. Second, it accounts for the variety of interventions mediators perform by using the concepts of face and facework. The article discusses what the findings mean in terms of mediation, the interaction order, and the institutional order.

KEYWORDS: conflict, dialogue, disagreement, discourse analysis, dispute mediation, face, institutional talk, interaction order, topic, mediator practices. 


\section{Author's Bionote}

I received my Ph.D. from School of Communication and Information, Rutgers, the State University of New Jersey, USA, in 2010 and my Candidate of Science (Kandidat Nauk) from Minsk State Linguistic University, Belarus in 2002. I am Assistant Professor at the Department of Communication, University of Massachusetts Amherst, USA. My general research interests include deliberation, disagreement management, social identity, and the coordination of actions in personal and public contexts. 
Practices of Topic and Dialogue Activity Management in Dispute Mediation

The article focuses on mediator practices to bring interaction back on track when participants of dispute mediation go off-task. Mediation is a form of dispute resolution that gives disputants an opportunity to manage their conflict with help of a third party, that is, a mediator. During the mediation sessions under study, the participants are gathered for the purpose of working out visitation and custody issues that arise from their divorce. The mediator's task is to get the participants to contribute to solving these issues. Mediators are to help people deal with their conflict, which can be face threatening. The mediator's actions can violate the disputants' negative or positive face. For example, letting one party tell a story that may be relevant for the discussion but depicts the other disputant unfavorably would be face threatening for that disputant. Another issue is that mediators' task is to lead the participants but, at the same time, they are not supposed to be authoritative. This can be summarized as a practical puzzle mediators contend with in performing their role as non-authoritative intervention (e.g., Jacobs, 2002; Aakhus, 2003).

In this respect, this study examines moves mediators make to perform interventions to bring the current state of activity more in line with mediation activity. It also accounts for the variety of interventions they perform by applying the concepts of face and facework. 
The concept of face was introduced by Goffman (1967), who defines face as "the positive social value a person effectively claims for himself [or herself] by the line others assume he [or she] has taken during a particular contact" (5). According to Goffman, face is social and public as it is an image that is revealed in the people' actions in the course of interaction. Another aspect of face is that it is situated, that is, it is associated with a particular identity (e.g., friend, client, mediator, parent) we present in a particular interaction. Face is claimed when interactants enact different roles and when other participants act toward them in the way that sustain that image. As face is social, public, claimed, and situated, the maintenance of face involves cooperation of all the participants of interaction.

However, people can perform actions that threaten face. Actions can threaten positive face (i.e., the person's wants to have his or her public image to be approved and ratified) and/or negative face (i.e., the person's wants to be free of impositions). These two kinds of face (negative and positive) are important aspects of Brown and Levinson's politeness theory (Brown, 1990; Brown and Levinson, 1987). According to Brown and Levinson, the concept of face plays an important part in selecting verbal strategies of politeness. The researchers distinguish five types of face threatening acts (FTA). Interactants can commit a FTA on record by saying it in a straightforward manner; on record with positive redressive actions (positive politeness); on record with negative 
redressive actions (negative politeness); off record by communicating intentions in an ambiguous way that allows to avoid accountability; and, finally, not to do a FTA. The acts form a continuum from most face threatening (bald on record) to less face threatening (not committing a FTA). Brown and Levinson claim that the selection of strategies is determined by power relationship between the interactants, solidarity or commonality, and face. The bigger the vertical and horizontal distances between them and the bigger risk of imposing on a person or undermining her or his image, the less face-threatening act is committed.

The concept of face is a crucial feature of the organization of interaction as the need of a presentational self to be achieved and maintained puts constraints on interaction (Goffman, 1983). The interactants have obligations to sustain their own face and the face of other participants in the course of interaction, which lets the participants get where they are heading in their interaction.

Goffman's and Brown and Levinson's focus on face was how it happens in ordinary interaction. What is interesting in the present study is how this concept plays in institutional context. From the analysis, I make two specific claims. First, I suggest that the participants, especially the mediators, face the puzzle of trying to produce institutional talk within the fact of the interaction order (Goffman, 1983) and that the mediators' interventions are tailored to sustain the interaction order and the institutional order. In the 
course of mediation sessions, the interaction order and the institutional order are cooccurring. Competing demands of the interaction order and the institutional order present an interactional dilemma for the mediators. The mediators construct their interventions in the way that would keep the disputants in the frame of the mediation activity and would not threaten their face at the same time. Second, I argue that the participants co-design the interactivity. The mediators use local resources, that is, what the parties make available in the course of the interaction, to shape the discussion. The empirical findings provide grounds for theorizing about the nature of mediation talk as a type of institutional interaction.

In the following sections, I will discuss research on practices of disagreement management in institutional context with a particular focus on mediation talk, describe the methodological aspect of the study and the data, provide the analyses of examples from mediation sessions, and discuss the findings.

\section{Disagreement management in institutional talk}

One of the areas of research on conflict talk is how people manage interaction, especially in the context of disagreement, both in everyday conversations and institutional talk. Of special interest is how participants acting in their institutional role intervene to keep interaction on track, which can be evident, for example, in the work of facilitators, 
mediators, news interviewers, and radio hosts (e.g., Black and Wiederhold, 2014;

Greatbatch, 1992; Hutchby, 1996; Jacobs, 2002).

Some research shows how the format of institutional talk creates opportunities for taking control over interaction, and managing disagreement in particular (e.g., Drew, 1992; Garcia, 1991; Greatbatch, 1992). For example, a more formal system of turn-taking in news interviews (Greatbatch, 1992) and mediation (Garcia, 1991) serves as a resource to mitigate disagreement. Participants in these institutional settings often address an institutional agent rather than another participant, and thus there is a delay in the production of an oppositional move. Interactional asymmetries in terms of resources, knowledge, roles can give an advantage to one participant over the other. In court hearings, where an attorney and a witness have fixed roles of a questioner and an answerer, attorneys exploit the question-answer format to present their $\operatorname{argument}^{1}$ by means of questions in such a way that it would lead to drawing desired conclusions, as they have more control over selecting items to address, making connections between pieces of testimony, and inferences that can be made based on how questions and information are juxtapositioned (Drew, 1992). In call-in radio talk, the asymmetry between the first and second positions in argument allows a radio host to have more interactional power in an argumentative exchange. According to Hutchby's (1996) Action-Opposition model, an oppositional move is the primary element in an argument, as it "subsequently formulates the prior action as an 
arguable" (23). In radio talk, callers are expected to express their opinion on some social issue and to set their own agenda for a discussion. However, it is a radio host who chooses what gets arguable and shapes the direction of interaction, as the structure of calls puts him/ her in a second position. The second position in the sequence of moves gives an opportunity to the host to challenge a caller's position in a number of ways without expressing his/her own position, and thus callers find themselves defending their position. In mediation sessions, on the contrary, the first speaker has an opportunity to set grounds on which discussion takes place and to put constraints on the opposing disputant's actions (Garcia, 2010), which mediators have to take into account when they manage interaction. Institutional agents' behavior in conflict talk is another focus of scholarly inquiry. Some studies are concerned with the question of neutrality (e.g., Donohue, 1991; Garcia, 2000; Garcia et al., 2002; Glenn, 2010; Greatbatch, 1992; Heisterkamp, 2006; Jacobs, 2002; Wall and Chan-Serafin, 2014). For example, mediators manage to appear impartial using three tactics: indirect advocacy (e.g., in the form of asking questions), framing advocacy (summarizing what disputants say), and equivocal advocacy (e.g., providing information to disputants) (Jacobs, 2002). Among other techniques that mediators use to display a stance of neutrality are self-labeling, unbiased paraphrasing, perspective display series, conversational footing, and avoidance of a direct response to disputants' information-seeking attempts (Heisterkamp, 2006). For example, mediators may explicitly 
label themselves as a neutral party (a self-labeling method) or they can seek an opinion or perspective of a disputant without providing their own (perspective display series).

At the same time, research shows that institutional agents play an active role in shaping talk. This is evident in different techniques they use to gear interaction in an institutionally preferred direction and interventions they make to bring talk back on track when it goes off-task or reaches impasse. For example, Hutchby (1996) identifies validity challenge, formulating ${ }^{2}$, and attributing a position as argumentative devices that radio hosts use to pursue controversy. The latter one is also a feature of attorneys' strategies in crossexaminations (Drew, 1992). Studying the role of trial court judges in shaping a structure of talk, Philips (1990) finds out that judges play an active role in this process by offering a third position, initiating a position, and arguing against a position they are going to rule against.

Research on mediation identifies a range of communication practices mediators use to put constraints on the development of mediation talk such as requesting directives, framing (Donohue, 1991), story summarizing, empowerment, emotion work (Garcia et al., 2002), evaluations (Wall and Chan-Serafin, 2014), and specific solicits to narrow the boundaries of the proposal (Garcia, 2000). Mediators can ask for clarification, offer compromises, and negatively sanction disputants to terminate argument between them (Greatbatch and Dingwall, 1991; Greco Morasso, 2011) and ignore disputants'stance 
displays in order to move toward an agreement (Glenn, 2010). Mediators can advance an institutionally preferred form of interactivity by introducing institutionally appropriate topics, dialogue activities, and participants' identities and by discouraging institutionally dispreffered ones (Greco Morasso, 2011; Vasilyeva, 2012a, 2012b, 2015). Analyzing messages mediators produce to manage impasse, Aakhus (2003) identifies three strategies that mediators use to shape disagreement space in the course of mediation sessions. In managing impasse, they use linguistic devices to redirect the focus of the discussion, to temporize the dispute (i.e., asking participants to develop temporary arrangements), and to relativize facts (i.e., discounting the grounds on which a disputant escalates the dispute).

Some of the mentioned strategies, for instance, formulations, editing and reframing are also evident in the work of other third parties such as facilitators and judges of small claim courts (Black and Wiederhold, 2014; Sprain et al., 2014; van der Houwen, 2009). For example, facilitators of public deliberation frame issues as contentious to terminate the discussion on aspects that cannot be resolved (Sprain et al., 2014). In their turn, judges use different types of formulations (e.g., checking formulations, bridging formulations, legal formulations, and judgment formulations) to constrain and develop subsequent interaction (van der Houwen, 2009).

When institutional agents make a decision to intervene, they also take into consideration the nature and the timing of disagreement and the relational climate of 
participants (Black and Wiederhold, 2014). For example, mediators' employment of neutral or more assertive strategies depends on whether the disputants move to agreement or not (Wall and Chan-Serafin, 2014).

The studies discussed in this section contribute to understanding the role of institutional agents in crafting interactivity. The current study continues this line of research and focuses specifically on mediators' practices to bring interaction back on track, when disputants go off-task.

\section{Method and data}

The study uses the method of discourse analysis that focuses on exploring the language use in context. An existing collection of 18 transcripts from audio recordings of mediation sessions at a mediation center in the western United States served as a source of interactional data. The transcripts used in the present study were made by Deborah WeiderHatfield for Dr. William Donohue's project on communication practices in divorce mediation (Donohue, 1991). These transcripts were made available to me by Dr. Scott Jacobs. The transcription of the audiotapes followed the simplified scheme developed for conversation analysis. The transcripts capture what was said (words, cut-offs, ums, uhs, and unintelligible talk) and include interruptions, overlaps, and pauses. Due to the absence of audiotapes, there was no chance to update these transcripts according to a more current version. Given the actual nature of the data, it is not possible to capture all the aspects of 
interaction (e.g., participants' nonverbal actions) that can affect how the interaction unfolds. However, these data make it possible to analyze the participants' language behavior and interactional resources the mediators use to shape mediation talk.

The participants of the mediation sessions are divorcing or divorced couples. The mediation sessions are set up for the disputants to develop arrangements for child care such as child custody, visitation rules, and support. Eight different mediators conducted these sessions. All cases except one lasted one session. The length of sessions varied but in the majority of cases it was about 2 hours.

For the analysis, I specifically look at moves the mediators make to terminate a topic or a dialogue activity that they treat as institutionally inappropriate and the local context of their occurrence. The interventions were examined in terms of the target of the termination (i.e., a topic or a dialogue activity), the form, and the account for terminating a topic or a dialogue activity or its absence. The following section describes different types of interventions mediators perform.

\section{Types of interventions}

In the opening speech, the mediators introduce the nature of mediation activity and make moves to keep the participants focused on it throughout the session. However, the disputants can take interaction in a different direction. When the participants drift away 
from the institutionally defined task, the mediators construct their interventions in a number of ways to signal that the disputants went off-task in the course of the session.

Interventions vary in forms but they can be put into two major categories, namely, direct and indirect interventions, depending on whether the interventions include a straightforward message to terminate an off-task topic or dialogue activity or not. First, I will describe direct interventions.

\section{Direct interventions}

Direct interventions are mediators' contributions where they specifically point out matters participants should not talk about or a dialogue activity that the disputants should not engage in. The interventions fall in the following categories: mediator-centered interventions, parties-centered interventions, session-centered interventions, and noncentered interventions. The interventions differ in terms of types of accounts the mediators provide to terminate an off-task topic or dialogue activity or lack of them and the degree of threat they present for the parties' face.

Mediator-centered interventions. In mediator-centered interventions the reason for not discussing a certain issue or not engaging in a dialogue activity involves a mediator. In other words, the mediator is held accountable for terminating a topic or a dialogue activity. It can be attributed to 1) the mediator's unwillingness to do that or 2) the mediator's 
incompetence in a specific area. Excerpt 1 illustrates the former, while excerpt 2 is an example of the latter.

In excerpt 1 , the (ex)-wife (W) initiated a topic on some past event that depicts her (ex)-husband $(\mathrm{H})$ in a negative way. The mediator $(\mathrm{M})$ intervenes to close up the topic indicating lack of interest in certain subjects.

Excerpt 1

$6 \mathrm{~W}$ : [Well, ] Well anyhow Oscar's rather hesitant of Jack, he's a little afraid of him, and I'll have to bring up the past be- because of the past and um=

$7 \mathrm{M}: \quad=$ Yeah by the way let me just say, there are some things about- about the past that are important to understanding, uh further than that I'm not interested. It's not a matter of who's right or wrong or good or bad or moral or immoral or any of those things, I don't care.

Prior to this episode, $\mathrm{M}$ asked $\mathrm{H}$ and $\mathrm{W}$ to share what they had decided in terms of agreement. Instead $\mathrm{W}$ makes a claim that there is a relationship issue between $\mathrm{H}$ and Oscar and tries to bring in some past event to support her claim. Although W does not directly accuses $\mathrm{H}$ of his behavior, mentioning the child's fear of his father undermines H's image. On the one hand, W's move is topically incoherent with the topic M initiated; on the other hand, it can also lead to a conflict situation as it presents a threat to H's face. M intervenes while W's turn is still in progress (the conjunction "and" signals that W has not completed 
her turn yet). $M$ emphasizes his role in making a decision about what is proper or improper to discuss. M is "not interested" and does not "care" about the past (e.g., events that depict a disputant unfavorably) unless it is important for understanding the situation.

Using this type of intervention, the mediator acts as an authority and expresses interactional power to terminate the development of off-task activity or topic. The mediator does not control the outcome of the proceedings like a judge would but the disputants do. The mediator, however, can exercise control over the process. Interventions of this type are face-threatening in a greater degree as they do not tone down the face threat and do not compensate for that (although the move is slightly mitigated with help of the agreement marker "yeah" at the beginning of the turn). They threaten the disputants' positive face, as they show no concern for their wants (e.g., to talk about certain events). They are also threats to their negative face as they impose on them (e.g., when the mediator states what he or she wants the participants to do). In the context of mediation activity, these face-threatening acts are less offensive than in ordinary interaction due to the power factor. Although mediators do not have formal power as a judge, they have a formal role and exercise more interactional power due to their participation role in mediation.

The second type does not carry this authoritative character. Here, to stop the development of the topic, the mediators bring in into the conversation their lack of knowledge to discuss certain things or abilities to take actions regarding them. For 
example, in excerpt 2, M points out his lack of ability to do anything in terms of financial issues.

Excerpt 2

98H: This is our fifth time in court, so ((PAUSE)) ( ) community property, there won't be any left (to), pay the attorneys and cour[t costs ( )

99W:

[But I made them

compulsive two months ago they have not said yes-no counter offered or even spit in my face. So I do not believe that it is my fault that this thing has to keep going back to court $=$

100H: =Her-, basically her proposal ((PAUSE)) which for some reason she can't- [can't ] 101M:

you know I don't really need to get in, into the financial proposals 'cause I-, not-, nothing I can do about that anyway you know and

Prior to this episode, M inquired about the (ex)-couple's return date to court and received a conditionally relevant response. In the following turns, however, $\mathrm{H}$ brings in into the discussion expenses that going to court involves and the consequences of the court process on the parties' financial situation (turn 98). W's treats H's move as an attack at her, the evidence of which is her oppositional move (turn 99). She initiates her move while H's turn is still in progress, starts her move with the disagreement marker "but", denies her 
responsibility for this situation ("I do not believe that it is my fault") and provides support for her claim (i.e., she made a proposal but has gotten no response to it). $\mathrm{H}$ latches his move to W's talk and starts delving into W's proposal. H's move seems to be criticism of W's action. $\mathrm{M}$ interrupts him and points out that they should not discuss this issue, as he cannot do anything in terms of financial matters. $M$ mitigates his intervention with the hesitation marker "well", the phrase "you know", and the adverb "really".

Employing this kind of intervention, the mediator avoids a responsibility to deal with certain issues. As the mediator cannot help the disputants solve these issues due to his or her incompetence or lack of knowledge, discussing them is pointless. In this way, the mediator terminates the discussion in a less threatening manner. They mitigate the threat to the participants' positive face by making themselves vulnerable, as revealing themselves as lacking knowledge or having no power to deal with certain issues present a threat to their own positive face.

It appears that the shape interventions take has to do with the type of off-task topics the disputants initiate. While the mediator cannot claim incompetence in dealing with certain past events, the disputants' bringing in financial issues or physical abuse allows mediators to terminate the discussion on the grounds of their inability to deal with the issues. 
Parties-centered interventions. In parties-centered interventions, the account for terminating the discussion has something to do with the disputants. For example, the reason for not discussing a certain issue can be circumstances in the parties' situation, which is illustrated by excerpt 3 . Here, the grounds for terminating the discussion over financial matters are the parties' unstable situation.

\section{Excerpt 3}

74W: $\quad$ OK and I have to sell the house because, um, since my husband moved out he hasn't paid any of the payments=

75H: [=Right, right ]

76W: [We got-, we got] the house ok he's paid [one payment and half another payment] 77M:

let's not talk about the house and let's not talk about money right now because I know that you're in the early stages of your divorce and your residences may change because of financial situations and everything

78W: ((cough cough))

79M: but let's talk about the children being with you and living with him wh- what do you propose in terms of the children's time with each of the two parents

Prior to this episode, $\mathrm{M}$ asked $\mathrm{W}$ to share her custody plan. In turns 74 and 76, W, however, focuses on financial problems, which $\mathrm{M}$ points out as improper in turn $77 \mathrm{~W}$ 
accuses $\mathrm{H}$ of not paying for the house (turn 74). H's move latches to W's talk at a possible completion point, which results in the overlap of their turns. Although $\mathrm{H}$ uses the agreement marker "right", W treats his move as an expression of disagreement, which is evident in the self-correction of her accusation (“ok he's paid one payment and half another payment”). Similar to excerpt 1 , the disputants' actions can lead to digression from the main topic and conflict escalation. $\mathrm{M}$ intervenes while $\mathrm{W}$ 's move is still in progress. $\mathrm{M}$ directly asks the participants not to talk about money and residence as their situation can change (turn 77) and asks them again to share their proposals (turn 79).

In this way, the mediator makes a move to refocus the discussion on the custody issues, which is an institutionally appropriate topic, and to leave aside the financial issues that cannot be resolved during the mediation session. Bringing in into interaction the temporality of the disputants' situation and conditions makes the discussion over these issues fruitless. There is no point trying to make a decision in regard to matters that are going to change. In this way, the mediator makes a move to terminate the development of the off-task discussion in a non-threatening manner as the reason is attributed to circumstances that are out of control of the participants. The way the intervention is constructed, which aggregates the mediator into the collectivity ("let's not talk about the house"), decreases the social distance between the mediator and the disputants, which also 
contributes to decreasing the threat to the disputants' face, as it makes what sounds as criticism less threatening for the disputants' positive face.

Session-centered interventions. In session-centered interventions the termination of a topic or a dialogue activity is attributed to the fact that the matter is out of scope of questions that can be resolved during the mediation session or a dialogue activity is inappropriate for the session.

Excerpt 4 serves as an illustration of this category in regard to off-task topics. The focus of the preceding discussion was on H's visitation time. W does not mind $\mathrm{H}$ spending time with their daughter beyond weekends but she suggests that there should be some structure regarding visitation, as it is in the daughter's interests, as well as theirs. However, in response to W's comment, $\mathrm{H}$ raises a question of financial support, and $\mathrm{M}$ immediately makes a move to bring the topic to its end.

Excerpt 4

183W: It's just that she needs some structure to this. And so do we.

184H: $\quad$ You need some structure by having me pay for you

185M: Okay n[ow okay]

186W: [That has ] nothing to do with what I'm talking about Arnold

187M: Okay i[t- it ]

188W: [Money] has nothing to do with this at this point= 
189M: =It does and it doesn't all right?

190H: It does- [it does matter ]

191M: [What's real important-] what's real important Arnold is to come up with a plan that is good for Valerie. Apart from the money, Valerie simply needs to be with both of you.

192W: Right

193M: Okay after that's worked out then either the attorneys or the judge will work out the money.

In turn $184 \mathrm{H}$ brings in a financial issue and accuses $\mathrm{W}$ of an attempt to make him pay for her. W picks up this issue in turns 186 and 188. She resists the shift in the discussion and makes an oppositional move. W does not challenge H's claim but disagrees with the relevance of the financial matter to what has been discussed before. In turn $188, \mathrm{~W}$ specifies the statement she made in turn 186 changing "that" to "money" and mitigates her disagreement by temporizing the matter (i.e., "at this point"). In this way, she seems to orient toward staying focused on the task in terms of the topic and the activity. M intervenes in turns 185 and 187 with the topic termination marker "Okay". Both times M's turns get overlapped by W's moves. In turn 189, M latches his talk to W's move and expresses agreement with both disputants. In this way, $\mathrm{M}$ makes another attempt to bring interaction back on track and to prevent escalation of disagreement by aligning with both 
parties and stating that they have a point regarding the relevance of money to visitation arrangements. H, however, takes it as an opportunity to continue the discussion on the financial matter. His move can be seen as an oppositional one, as he agrees only with the first part of M's statement that represents his position. M immediately intervenes and takes an action to close up the topic. In turns 191 and 193, M pointed out that financial matters could be resolved by the attorneys or the judge but not during the session. In these turns, M addresses $\mathrm{H}$, and $\mathrm{W}$ expresses her alignment with $\mathrm{M}$ in turn 192 with the agreement marker "Right".

Similar to instances of mediator-centered interventions where the account for the termination of an off-task topic was the mediator's incompetence or lack of knowledge, types of topic the disputants initiate enable the mediators to shape their interventions in a less threatening way. While M's intervention in turn 185 may orient toward the possibility of H's attack to lead to a conflict situation, $M$ uses the inappropriateness of the topic rather than the activity to redirect interaction. The termination of the topic on the basis of impossibility to resolve it during the session decreases a threat to the disputants' positive face, as it invokes institutional constraints (and the power factor) rather than the mediator's personal unwillingness to deal with these issues. 
Session-oriented interventions are the ones that are task-related in a greater degree, as they explain the inappropriateness of a topic or a dialogue activity in terms of an obstacle to achieving an institutional goal of the encounter.

Non-centered interventions. Interventions of this type point out the violation of topic or dialogue activity appropriateness without providing any explanation why it is considered improper, which is illustrated by excerpt 5 .

Prior to this episode, the participants were discussing what to do in case the child gets sick. The discussion has gradually shifted to having an argument, and $\mathrm{M}$ intervenes to bring the interaction back on track by calling the parties to stop the dialogue activity.

\section{Excerpt 5}

87M: That's really sad you know?=

88W: $\quad=$ I know it's [sad ]

89M: [That] a child would be afraid to tell the parent she wants mother when she's with you or when she's with you that she wants to be with daddy= 5 turns omitted

95H: [She was] re- responding to you to (placate) you

96W: I don't wanna talk [(ask her, okay)]

97H: [That idea ] didn't come from you, you sat down and said and told her how upset you were. You put that idea in her head how you- how 
upset you were that you weren't with her she wanted to please you so she came back and said yes I want- I wanted you there, that idea didn't come from her she didn't ask for you once, she was fine with me ((PAUSE)) Okay and the reason I [didn't ]

98W: $\quad[(\quad)]$

99H: I didn'[t ]

100W: $\quad[$ I don't] believe you=

101H: =and the reas[on ]

102W: $\quad[$ I don't] believe a word you say

103M: Okay, let's stop that

In turns 87 and $89, \mathrm{M}$ makes a negative assessment of the situation when the child is afraid to express her wish to see her parent when she is staying with the other one. In the omitted part, $\mathrm{H}$ and $\mathrm{W}$ exchange a number of remarks that justify one's position while questioning the other parent's position in regard to this situation. W refers to her daughter's behavior as evidence of her fear of $\mathrm{H}$, which undermines H's image. $\mathrm{H}$ disagrees with W by stating that what the child said was provoked by W's mood (turn 95). W makes a move to withdraw from interaction by expressing her unwillingness to talk (turn 96) and suggests $\mathrm{H}$ should talk to their daughter. $\mathrm{H}$ accuses $\mathrm{W}$ of manipulating their child and provides the counterevidence to W's claims ("she didn't ask for you once" and 
“she was fine with me") (turn 97). W expresses her disbelief in what H says (turns 100 and 102). In this episode, W's and H's turns get overlapped; their oppositional moves are recycled without adding anything to their claims and present threats to the disputants' faces, which are the features of a dialogue activity of having an argument. M intervenes and makes it clear that the participants were involved in an inappropriate activity. In turn 103, he asks the participants in a straightforward manner to stop what they were doing (the termination marker "Okay" and the directive "let's stop that").

In this case, the mediator does not name this activity, that is, having an argument, directly and performs the intervention without redressive actions. Bald on record interventions maximize the efficiency of the action but do not minimize the face threat (Brown and Levinson, 1987). In this episode, the mediator intervenes to terminate the dialogue activity in a mitigated form by framing the directive to stop as a mutual action ("let's stop"), thus decreasing the face threat.

\section{Indirect interventions}

Mediators do not always state that a shift in activity happened and that topics or dialogue activities are inappropriate. They can redirect the conversation and refocus the parties on the task in a more indirect manner. For example, mediators can change the development of the interaction by ignoring an off-task topic a disputant introduces, by initiating a new topic, summoning, and reformulating. These moves are less face- 
threatening, as they do not question the inappropriateness of the disputants' actions overtly and, thus, do not present a threat to their positive face. The imposition is minimized, thus these actions also do not threaten their negative face. For example, the mediators use reformulating, ignoring a topic, and summoning at an earlier stage of going off-task to keep the disputants focused on the previous line of discussion in which all the parties are already engaged.

I will use reformulating to illustrate this category, as the space limit does not permit to give examples of all the techniques. In excerpt 6 the parties discuss visitation time, in particular, the situation when $\mathrm{H}$ cannot have the children on Wednesdays due to being away on a business trip. As the interaction progresses, disagreement arises over this issue, which leads to a shift in a dialogue activity. M intervenes by reformulating ${ }^{3} \mathrm{~W}^{\prime} \mathrm{s}$ position to refocus the disputants on the on-task activity.

\section{Excerpt 6}

85W: If you can't be there if you're not going to be there on Wednesday night, let me know and we'll have to decide on some period of time ahead and maybe we can switch it to either the Tuesday night prior or the Thursday night after.

86H: Well what about Monday night ((WHININGLY))

$87 \quad((\mathrm{PAUSE}))$

88W: You're having them until Monday morning on every other weekend, so I think 


\section{Monday nights}

89H: Jen, [I'm not out o]n vacation.

90W: [disruptive again]

91H: I'm not earning- [ earning money half of which goes

92W: $\quad$ [I didn't say that I said if you just brought them back Monday morning and they only get to see me after school I [think that's too disruptive.

93M:

[I think- I think what you're saying is that you will agree ((PAUSE)) to let him make up that time, but it has to be either Tuesday or Thursday=

94W: $\quad=$ of that same week

95M: The same week. ((PAUSE)) How long would you be gone?

96H: Like I said a couple a minutes ago, I'm normally-, I have to go back east, so I'm normally out ah three to four days one trip, and three to four on another.

In turn $85, \mathrm{~W}$ suggests what to do in case $\mathrm{H}$ cannot have their children on regular days and offers options. In turn $86, \mathrm{H}$ does not produce a conditionally relevant action as he does not directly accept or reject W's offer. However, the hesitation marker "well" and his counteroffer (i.e., Monday night), although framed as a request with help of the nonverbal cue "whiningly”, signal H's disagreement. The pause delays W's response, which is a sign of dispreferred action. W indeed indirectly declines H's request by 
indicating a shortcoming of H's position (turns 88 and 90). H's moves in turns 89 and 91 indicate that $\mathrm{H}$ treats W's objection as her unwillingness to agree to compensatory time in general, as he shifts from the specific issue of the visitation time on Monday to compensatory time as a whole by providing justification for his request. $\mathrm{H}$ makes a point that he is "not out on vacation", which can mean it is not his fault that he misses the visitation day as it is out of his control when to go on a business trip and he is not having fun while away (turn 89). In turn 91, he brings in financial issues pointing out that he is not earning enough money, half of which he has to spend (probably, on the children). In this way, he shows that his request for the compensatory time is legitimate and W's behavior is unreasonable and her reluctance to agree to this may be viewed as her desire to punish him. $\mathrm{W}$ denies all the implications and repeats again her argument that what $\mathrm{H}$ proposes is not good because it is disruptive (turn 92). Thus, she makes it clear that her concern is the interests of the children and her actions are not aimed at putting $\mathrm{H}$ in a disadvantageous position. However, this time she upgrades the assessment of H's proposal from "disruptive" to "too disruptive", which can be evidence that W's unwillingness to agree to making up the time on Monday nights is quite strong, and the chances to come to agreement on this matter are very low. The discussion is gradually shifting to having an argument. H makes moves that digress from the main issue of the discussion, that is, the visitation time, and brings in some aspects of his life situation. W, in her turn, sticks to the 
topic but focuses on a negative aspect of H's proposal. They also initiate their moves not at a possible completion point, which results in interruption and overlap of their turns. $\mathrm{M}$ intervenes to refocus the parties' attention from the problematic option to a more viable alternative (turn 93). M makes a move while W's turn is still in progress and reformulates what W has said before and emphasizes W's willingness to agree to the compensatory time, which W confirms by collaboratively completing the utterance (turn 94). In turn 95, M makes a shift to the activity of information gathering. In this way, $M$ does not let the argument develop and brings interaction back on track.

Formulations can perform different functions depending on the context (Gafaranga and Britten, 2004). For example, they are used to initiate the closing of a topic or a conversation (Gafaranga and Britten, 2004), to check understanding or to move a story along (van der Houwen, 2009), and to challenge an interlocutor (Hutchby, 1996). Similar to these findings, in this example, M's reformulation performs an additional function to summarizing. M does not simply reformulate W's words but also the action she supposedly performed, that is, agreeing to H's request. As M's job is to lead the disputants to some agreement, the focus on a positive aspect of W's move is related to M's agenda. M makes this move to avoid conflict and to keep the discussion on task. In this respect, this observation is in agreement with the previous research that shows how formulations are used to transform a client's account so that it would fit the institutional agent's project 
(Antaki et al., 2005; van der Houwen, 2009). The specificity of this action is that while it is addressed to one interlocutor and reformulates what she said, it is also meant for a third party involved in the interaction. The use of reformulation in this context is also different from the previous findings that it is not used to initiate the closing of the topic or the conversation but to bring the interaction back to an on-task activity.

The imposition in this case is minimal, thus, this intervention does not present a threat to the disputants' negative face. It also diminishes a threat to the disputants' positive face. It focuses on the (ex)-wife's willingness to agree to the changes and depicts her as a collaborator (the (ex)-wife's positive face). At the same time, it shows that the (ex)husband's wish is taken into consideration (the (ex)-husband's positive face).

To sum up, the mediators employ different types of moves to terminate the development of an off-task dialogue activity or topic and to enforce the institutional format of talk. These interventions vary in their directness. The general principle that appears to underlie interventions is the mediator's orientation toward the disputants' face. The intervention type depends on what materials are available to the mediator in a local context. In the next section, I will discuss how these empirical findings contribute to understanding mediation and the interaction order and the institutional order.

\section{Discussion}


In contrast to two parties trying to work their disagreement out themselves, their entry into mediation invited a mediator to take on some responsibility for the way the parties interact with each other. We can see how this is realized as the mediators in this study attempt to control topic and dialogue quality of the interaction. The mediators set up the agenda for the session, introduce topics for the discussion and dialogue activities to engage in, and manage topic and dialogue activity violations in different ways, from indicating directly what topics and dialogue activities are inappropriate to terminating their development in subtler ways. Topics that the mediators treat as institutionally inappropriate are the ones that deviate from the meeting agenda and are emotionally-loaded (e.g., financial issues, parties' negative behavior, parties' interests (see Vasilyeva, 2012a)). As for institutionally inappropriate dialogue activities, the mediators intervene when the discussion is shifting to having an argument (see Vasilyeva, 2012b), the constitutive features of which are interruptions, overlapping turns, recycled moves, oppositional moves that focus on the other disputant's negative features of character and actions (e.g., accusations, criticism) rather than discussion issues, and conditionally irrelevant responses. While in some cases, the mediators intervene immediately to prevent a shift in the discussion, for example, in regard to inappropriate topics (e.g., in excerpt 1), in other situations (e.g., in case of inappropriate dialogue activities), they may let the interaction develop before it becomes obvious that the disputants have digressed (e.g., excerpt 6). This can be explained by the 
fact that the mediators have to construct the interactivity on spot and whether the disputants' moves are productive or not is not always clear.

One of the difficulties that mediators face is that they cannot sanction parties for violating the rules of the discussion the way judges do (e. g., fining a person who misconducts). They can point out that violations happened and threaten disputants with a court appointed psychologist or losing control of decision making to a judge if they do not collaborate. However, mediators cannot really punish them for violations. The situation gets complicated as mediators have to manage violations in such a way as not to disrupt the interaction order themselves as this kind of intervention can threaten the parties' face. This is an issue because of the nature of mediation talk. Although it is a type of institutional talk, it is not that formal as, for example, court hearings. Thus, mediators are concerned not only with keeping the institutional order but also with enforcing the rules of ordinary interaction in a greater degree than it is done in more formal types of institutional settings. In a way, mediation ends up treating certain aspects of ordinary conversation as formal rules.

What we have here is a fundamental feature of the institutional/interaction order tension. Mediation is informal relative to other forms of dispute resolution, and yet there are constraints on what can go in a mediation session, so a certain kind of interactional dilemma arises, which is a variation on the widely diffused dilemma of face. For example, the participants of intellectual discussions in institutional settings encounter a dilemma of 
balancing the concerns for face and supporting intellectual standards (Craig and Tracy, 1995).

Where certain settings allow a third party to be authoritative, which, in a way, means a permission to be positive and negative face violating, mediators do not have this liberty. As face is an organizing feature of the interaction order, sustaining it becomes an issue for the mediator. Letting the dispute go is face-threatening for the participants. However, trying to get them talk in the ways preferred in mediation also carries face risk. Mediators deal with both. They have to find more subtle ways to hold interactants to a topic and a dialogue activity. Thus, the common practice of the mediators under study is not just to signal violations but also to provide an account why the topic is irrelevant. The mediators mitigate the disruption by 1) attributing the irrelevance to their lack of competence in certain areas (mediator-centered interventions), 2) identifying the raised issues as being out of scope of questions that can be solved in the mediation setting and thus shifting the responsibility to the institution itself (session-centered interventions), or 3) creating their intervention in the way that it seems that the parties are still in control of how the interaction should proceed (participant-centered interventions). Mediator-centered interventions framed as the mediator's unwillingness to discuss certain issues are more likely to threaten the participants' face. However, they are downgraded by being constructed as unnecessary rather than undesirable. Also, as the mediators act on behalf of 
the organization, their expression of lack of interest in certain issues can be understood not as personal indifference but professional one. Interestingly, even when the discussion shifts to a dialogue activity of having an argument, the mediators tend to use the inappropriateness of the topic rather than of the dialogue activity to bring interaction back on track. In this respect, the indication of topic violation appears to be less face threatening than pointing an inappropriate activity.

Keeping the interaction order is vital for the interaction processes, but it has to be taken into account that in institutional talk maintaining the institutional order comes to the forefront. While indicating the inappropriateness of disputants' moves may bear some threat to their face, it helps to keep the focus on the task and thus to sustain the institutional order. Also, the multi-party interaction gives a certain advantage to the mediator as they can opt to provide a conditionally relevant response to the other party, which makes the intervention less threatening. Thus, the mediators construct their interventions depending on moves the parties make and opportunities they provide. This is also evident in the dependence of the types of intervention on the subject matter of the discussion. For example, in this specific court financial issues or court process are off limits. When the disputants bring in these topics into interaction, the mediators dismiss them on the grounds of either being incompetent in these questions or considering these issues out of scope of the session. When the parties bring some past events, the mediators do not have this option 
and use other types of intervention (e.g., expressing their unwillingness to discuss a certain topic). Thus, all the participants are involved in constructing the interactivity.

Indirect ways to bring the interactants back on track allow mediators to stay neutral. It is not neutrality in the sense of avoiding taking someone's side but in the sense of being neutral to the interaction itself, that is, not being involved in some activity, for example, having an argument. In a way, it is possible to draw the parallel between these two ways mediators intervene into the discussion and the styles of therapeutic interventions such as interventionist and restrained types of therapy. In the restrained style, the therapist has to be “a distant, respectful questioner" (Minuchin et al., 1996: 13) who does not challenge clients, give opinions and is not "the complex, multifaceted person that she is outside of it" (13). In the interventionist therapy, the therapist is more active and engages in the activity, $\mathrm{s} /$ he is not afraid to impose an opinion, to use personal responses, and to challenge the participants (Minuchin et al., 1996). Mediators' indirect interventions are similar to this restrained therapy while their direct interventions are more like the interventionist style.

We tend to think about neutrality as a big objective and to think about it in terms of biased/unbiased actions. But it has to do with the interaction and its quality. As agents of organization, mediators take an obligation in terms of crafting interactivity and have to work with others to create an interaction of quality. Mediators are obliged to make the 
parties take responsibility for their actions. Facework is one of the things to deal with that. The interventions are constructed to involve the disputants into the design of the quality. To conclude, the mediators employ different resources to keep the disputants on track and to gear them towards reaching an agreement. When the disputants go off-task, the mediators employ different types of intervention that vary in their directness and depend on the local context. Interventions differ in terms of managing multiple goals and demands that the interaction presents. They are organized by the sense of preserving the interaction order but also by having a particular type of interaction, that is, mediation. 


\section{References}

Aakhus M (2003) Neither naïve nor normative reconstruction: Dispute mediators, impasse, and the design of argumentation. Argumentation: An International Journal on Reasoning 17: 265-290.

Antaki C, Barnes R and Leudar (2005) Diagnostic formulations in psychotherapy. Discourse Studies 7: 627-647.

Barnes R (2007) Formulations and the facilitation of common agreement in meetings talk. Text \& Talk 27: 273-296.

Black LW and Wiederhold A (2014) Discursive strategies of civil disagreement in public dialogue groups. Journal of Applied Communication Research 42: 285-306.

Brown P (1990) Politeness theory: Exemplar and exemplary. In: Rock I (ed.) The Legacy of Solomon Asch: Essays in Cognition and Social Psychology. Hillsdale, NJ: Lawrence Erlbaum, pp. 23-38.

Brown P and Levinson SC (1987) Politeness: Some Universals in Language Usage. Cambridge: Cambridge University Press.

Childs C (2015) Formulations. In: Tracy K, Ilie C and Sandel T (eds.) The International Encyclopedia of Language and Social Interaction. John Wiley \& Sons, pp. 1-5.

Craig RT and Tracy K (1995) Grounded practical theory: The case of intellectual discussion. Communication Theory 5: 248-272. 
Donohue W (1991) Communication, Marital Dispute, and Divorce Mediation. Hillsdale, NJ: Erlbaum.

Drew P (1992) Contested evidence in courtroom-examination: The case of a trial for rape. In: Drew P and Heritage J (eds.) Talk at Work. Cambridge: Cambridge University Press, pp. 470-520.

Garcia AC (1991) Dispute resolution without disputing: How the interactional organization of mediation hearings minimizes argument. American Sociological Review 56: 818835.

Garcia AC (2000) Negotiating negotiation: The collaborative production of resolution in small claims mediation hearings. Discourse and Society 11: 315- 343.

Garcia AC (2010) The role of interactional competence in mediation. Conflict Resolution Quarterly 28: 205-228.

Garcia AC, Vise K and Whitaker SP (2002) Disputing neutrality: A case study of a bias complaint during mediation. Conflict Resolution Quarterly 20: 205-230.

Gafaranga $\mathrm{J}$ and Britten N (2004) Formulation in general practice consultations. Text 24: $147-170$.

Glenn P (2010) A mediator's dilemma: Acknowledging or disregarding stance displays. Negotiation Journal 26: 155-162. 
Goffman E (1967) On face-work: An analysis of ritual elements in social interaction. In: Interaction Ritual. Garden City, N.Y.: Anchor Books, pp.5-45.

Goffman E (1983) The interaction order. American Sociological Review 48: 1-17.

Greco Morasso S (2011) Argumentation in Dispute Mediation: A Reasonable Way to Handle Conflict. Amsterdam/Philadelphia: John Benjamins.

Greatbatch D (1992) On the management of disagreement between news interviewees. In: Drew P and Heritage J (eds.) Talk at Work. Cambridge: Cambridge University Press, pp. 268-301.

Greatbatch D and Dingwall R (1991) Argumentative talk in divorce mediation sessions. American Sociological Review 62:151-170.

Heisterkamp BL (2006) Conversational displays of mediator neutrality in a court-based program. Journal of Pragmatics 38, 2051-2064.

Houwen F van der (2009) Formulating disputes. Journal of Pragmatics 41: 2072-2085. Hutchby I (1996) Confrontation Talk: Arguments, Asymmetries, and Power on Talk Radio. Mahwah, NJ: Lawrence Erlbaum Associates.

Jacobs S (2002) Maintaining neutrality in dispute mediation: Managing disagreement while managing not to disagree. Journal of Pragmatics 34: 1403-1426. 
Jacobs S and Jackson S (1981) Argument as a natural category: The routine grounds for arguing in conversation. The Western Journal of Speech Communication 45: 118132.

Minuchin S, Lee W-Y and Simon G (1996) Mastering Family Therapy: Journey of Growth and Transformation. New York: John Wiley \& Sons.

Nir B, Dori-Hacohen, G and Maschler Y (2014) Formulations on Israeli political talk radio: From actions and sequences to stance via dialogic resonance. Discourse Studies 16: 534-571.

Philips S (1990) The judge as third party in American trial court conflict talk. In:

Grimshaw AD (ed.) Conflict Talk: Sociolinguistic Investigations of Arguments in Conversations Cambridge: Cambridge University Press, pp. 85-117.

Sprain L, Carcasson M and Merolla AJ (2014) Utilizing “on top” experts in deliberative forums: Implications for design. Journal of Applied Communication Research 42: 150-167.

Vasilyeva AL (2012a) Topics as indication of being on-task/off-task. Empedocles: European Journal for the Philosophy of Communication 3: 61-82.

Vasilyeva AL (2012b) Argumentation in the context of mediation activity. Journal of Argumentation in Context 1: 209-233. 
Vasilyeva AL (2015) Identity as a resource to shape mediation in dialogic interaction. Language and Dialogue 5: 355-380.

Wall JA Jr and Chan-Serafin S (2014) Friendly persuasion in civil case mediations. Conflict Resolution Quarterly 31: 285-303. 
Notes

${ }^{1}$ Jacobs and Jackson (1981) identify a set of "clear" cases of argument: 1) making arguments in the course of having an argument, which is a prototypical case of argument, where disagreement is sustained over a number of turns and is closely related to an issue stated in the original speech act; 2) having an argument without making arguments, that is primitive argument or quarrel, where interactants recycle prior moves in aggravated form, make insults, give commands, and the like; and 3) making arguments without having an argument, that is a conversational exchange that involves the construction of an argument without having disagreement. In the present study, the focus is mostly on having-anargument.

${ }^{2}$ Formulations are a regular feature of institutional talk, for example, radio talk (Hutchby, 1996; Nir et al., 2014), meetings (Barnes, 2007), medical encounters (Antaki et al., 2005; Gafaranga and Britten, 2004), and legal settings (van der Houwen, 2009).

"I use the term "reformulation" rather than "formulation" as, according to Childs (2015), "as conversation already consists of a series of formulations, this phenomenon may be more accurately described as reformulation" (4). It is especially relevant in this case, as in the previous turn W corrects H's interpretation of what she said and summarizes her position. M, in their turn, reformulates W's position. 